M.I. Baranov, S.V. Rudakov

\title{
CALCULATION-EXPERIMENTAL DETERMINATION OF THE AVERAGE NUMBER OF QUANTIZED LONGITUDINAL ELECTRON DE BROGLIE HALF WAVES IN A CYLINDRICAL CONDUCTOR WITH PULSED AXIAL CURRENT
}

Purpose. Implementation of calculation-experimental determination of average number $n_{0 m}$ of the quantized longitudinal electron de Broglie half waves of length $\lambda_{e z m} / 2$ in the metal cylindrical conductor with the pulsed axial current of high density. Methodology. Scientific bases of theoretical electrophysics and quantum physics, theoretical bases of the electrical engineering, electrophysics bases of technique of high-voltage and high pulsed currents. Results. The results of calculation-experimental estimations of average number $n_{0 m}$ of the quantized longitudinal electron de Broglie half waves in the round continuous zincked steel wire of radius $0.8 \mathrm{~mm}$ and of length $320 \mathrm{~mm}$ with aperiodic pulsed axial current $i_{0}(t)$ of temporal shape $9 \mathrm{~ms} / 160 \mathrm{~ms}$ of high density (at its amplitude of $\delta_{0 m}=0.37 \mathrm{kA} / \mathrm{mm}^{2}$ ). It is shown that in examined case the numeral value of the average quantized number from data of calculation and experiment makes $n_{0 m}=9$, and test average length of quantized longitudinal electron de Broglie half waves in the indicated steel wire appears approximately equal to $\lambda_{e z m} / 2 \approx 34 \mathrm{~mm}$. Electrophysical results are confirmed during the high current high temperature experiment conducted by a powerful high-voltage equipment calculation information on the choice of average value of quantized number $n_{0 m}$ for longitudinal "hot» areas of the width $\Delta z$ of the wire, different anomalous enhanceable concentration of drifting lone electrons and accordingly temperature of Joule heating. Originality. On the basis of the known conformities to the law of atomic and quantum physics new quantum-mechanical calculation correlation is obtained for determination in a metallic conductor with axial current of conductivity $i_{0}(t)$ of different type (direct, alternating and pulsed) of average number $n_{0 m}$ of the quantized longitudinal electron de Broglie half waves and accordingly longitudinal "hot» areas of the width $\Delta z$ of periodic localization along the conductor of drifting lone electrons. Practical value. Obtained results allow to make an evaluation prognosis on finding of possible places of longitudinal periodic localization of drifting lone electrons on narrow areas of the width $\Delta z$ of current-carrying parts of power wires and cables of objects of electrical power energy, production and dwellings apartments, showing up most strongly (expressed) in malfunctions of operation of cableconductor products with the currents of short-circuit and high current density. References 26, figures 4 .

Key words: metal conductor, pulsed current, calculation-experimental determination of the average number of quantized longitudinal electron de Broglie half waves and electron localization zones in a conductor.

Представлені результати теоретичних і експериментальних досліджень, які пов'язані з визначенням усередненого числа $n_{0 m}$ квантованих подовжніх електронних півхвиль де Бройля в металевому провіднику з імпульсним аксіальним струмом провідності великої щільності. Отримані результати вказывют на квантово-хвилевий характер протікання імпульсного струму провідності в цьвому провіднику, щุо приводить до виникнення в його структурі квантованої подовжньої періодичної локалізації вільних електронів, щцо дрейфують, на ділянках шириною Аz. Дані зони локалізації електронів відрізняються підвищеною температурою нагріву. Бібл. 26, рис. 4.

Ключові слова: металевий провідник, імпульсний струм, розрахунково-експериментальне визначення усередненого числа квантованих подовжніх електронних півхвиль де Бройля і зон локалізації електронів в провіднику.

Представлены результаты теоретических и экспериментальных исследований, связанных с определением усредненного числа $n_{0 m}$ квантованных продольных электронных полуволн де Бройля в металлическом проводнике с импульсным аксиальным током проводимости больщой плотности. Полученные результаты указывют на квантово-волновой характер протекания импульсного тока проводимости в этом проводнике, приводящий к возникновению в его структуре квантованной продольной периодической локализации дрейфующих свободных электронов на участках шириной $\Delta$. Данные зоны локализации электронов отличаются повышенной температурой нагрева. Библ. 26, рис. 4.

Ключевые слова: металлический проводник, импульсный ток, расчетно-экспериментальное определение усредненного числа квантованных продольных электронных полуволн де Бройля и зон локализации электронов в проводнике.

Introduction. A number of scientific publications in recognized domestic and foreign Journals and monographs have been devoted to theoretical and experimental studies of the quantum-wave nature of the electric conduction current in cylindrical metal conductors [1-11]. The results of these studies are fundamental in nature and allow to take a fresh look at the quantum mechanical processes of propagation and localization in the crystal structure of the metal of the indicated conductors of their drifting collectivized free electrons, which possess wave properties and are characterized by their de Broglie wavelengths $\lambda_{e}[12,13]$. As is known, for the wavelengths $\lambda_{e}$ of electron waves propagating in a metal of a cylindrical conductor with current in its longitudinal and radial directions, the fundamental relation from the field of wave mechanics (quantum physics) holds, obtained in 1924 by the outstanding French theoretical physicist Louis de Broglie and having the following classic form $[12,13]$ :

$$
\lambda_{e}=h /\left(m_{e} v_{e}\right),
$$

where $h=6.626 \cdot 10^{-34} \mathrm{~J} \cdot \mathrm{s}$ is the Planck constant; (C) M.I. Baranov, S.V. Rudakov 
$m_{e}=9.109 \cdot 10^{-31} \mathrm{~kg}$ is the rest mass of the electron; $v_{e}$ is the velocity of motion (drift) of free electrons in the crystalline structure of the material of the conductor.

According to [1-13], the behavior of free electrons in a metal conductor of a cylindrical shape is described by the corresponding Schrödinger wave $\psi$-functions (they were first proposed and obtained in an analytical form at the beginning for coupled electrons of hydrogen-like atoms when solving the corresponding wave equation (it entered the history of modern physics as Schrödinger equation) by the outstanding Austrian theoretical physicist Erwin Schrödinger in 1926 [14]), varying in space and time according to the harmonic law and square whose module determines the probability density of their (electrons) being in a particular place in the cylindrical volume of the conductor. In this regard, the most probable places of drift of free electrons under the action of applied to the opposite ends of the conductor constant, alternating, or pulsed electric voltage of free electrons in the conductor metal will be those that correspond to the amplitudes of the Schrödinger wave $\psi$-functions and, accordingly, the amplitudes of the electron waves of length $\lambda_{e}$, spatio-temporal changes of which also occur in harmonic law. In addition, the wave distributions of drifting free electrons in the metal structure of any conductor obey the fundamental principle of quantum mechanics - the Heisenberg uncertainty relation $[12,13]$, formulated by the outstanding German theoretical physicist Werner Heisenberg in 1927 [14] and having for longitudinal $z$ and radial $r$ coordinates of a cylindrical conductor with current the following canonical form:

$$
\begin{aligned}
& m_{e} \Delta v_{e z} \Delta z \geq h / 4 \pi ; \\
& m_{e} \Delta v_{e r} \Delta r \geq h / 4 \pi,
\end{aligned}
$$

where $\Delta z, \Delta r$ are, respectively, the uncertainties of the longitudinal and radial coordinates of free electrons drifting in the structure of the material of the conductor; $\Delta v_{e z}, \Delta v_{e r}$ are the uncertainties of the longitudinal and radial components of the drift velocity $v_{e}$ of the electrons in the conductor material, respectively.

It follows from (2) and (3) that even for known (numerically specified) values of the velocities $\Delta v_{e z}$ and $\Delta v_{e r}$ of drifting free electrons, their spatial location in the cylindrical volume of the material of the conductor with current remains undefined and quantitatively determined by the quantities $\Delta z$ and $\Delta r$, respectively. Taking into account the above physical (statistical) interpretation of Schrödinger wave $\psi$-functions, proposed in 1926 by the outstanding German theoretical physicist Max Born [14], the midpoints of the indicated $\Delta z$ and $\Delta r$ values for drifting free electrons will correspond to the amplitudes of electron waves of length $\lambda_{e}$.

With the numerical value of the longitudinal velocity $v_{e z}$ of the drift of free electrons in the copper conductor (respectively, and the numerical value of its uncertainty $\Delta v_{e z}$ ), in the limit of, for example, for the short circuit (SC) mode in the electric circuit (with a longitudinal current density $\delta_{e z}$ of about $1 \mathrm{kA} / \mathrm{mm}^{2}$ [15]), about 37 $\mathrm{mm} / \mathrm{s}$, it follows from (1) and (2) that the length $\lambda_{e z} / 2$ of the de Broglie electron half wave in this metal of the conductor will be numerically about $9.8 \mathrm{~mm}$, and the $\Delta z$ value of the longitudinal localization of drifting free electrons in a conductor - about $1.56 \mathrm{~mm}$. It can be seen that in the case under consideration (in the SC mode), the quantities $\lambda_{e z} / 2$ and $\Delta z$ take macro-sizes commensurate with the transverse dimensions of the real conductors used in electrical engineering and the electric power industry. In this regard, for this case, wave manifestations in the conductor metal of drifting free electrons, leading to local periodic overheating of the conductor metal in sections of width $\Delta z$, can be physically detected and recorded using measuring equipment (for example, a thermal imager or camera). As for the random (thermal) motion of free electrons in a copper conductor without conduction current (before applying an electric voltage to it), then in this case their highest speed, determined according to the Fermi-Dirac quantum statistics by the Fermi energy $W_{F}$ $[12,13]$, takes numerical value of about $1.6 \cdot 10^{6} \mathrm{~m} / \mathrm{s}$. Substituting this value of the electron velocity in (1) and (2), we find that for this case (the initial state of the «electron cloud» of the conductor), the desired values of $\lambda_{e} / 2$ and $\Delta z$ take nano-sizes, respectively, equal to approximately $0.23 \mathrm{~nm}$ and $0.036 \mathrm{~nm}$. Therefore, it is not possible for the researcher to identify local manifestations of the wave properties of free electrons randomly moving in its interatomic space and their influence on macroscopic electrophysical processes (for example, on the contact potential difference of metals, thermoelectricity [12], etc.) that occur in conductors.

The above quantitative estimates indicate that, due to the relatively small values of the drift velocities $v_{e}$ of free electrons in the crystalline structure of the metal of the conductor (for electric power industry, not more than $1 \mathrm{~m} / \mathrm{s}$ ), their wave properties will significantly affect the processes of their spatial distribution in metal conductors and, accordingly, on the processes of Joule heat release in their material.

When studying the behavior of drifting free electrons in conductor metal with conduction current, it is imperative that the quantum nature of all processes occurring in the microworld of matter be taken into account. Therefore, solutions of partial differential equations describing the wave distributions of these electrons in a conductor will be characterized by eigenvalues integers $n_{0}=1,2,3, \ldots$ which are called quantum numbers in quantum physics [12-14].

When studying the processes of formation and propagation of drifting free electrons in a metal conductor, one should also take into account the fundamental «principle of prohibition» formulated in 1925 by the outstanding Austrian theoretical physicist Wolfgang Pauli [14] regarding the properties of bound electrons in an atom of any substance. According to the «Pauli principle of prohibition», only one bound electron can be on the electron shells of an atom of matter, having a corresponding and characteristic quantitative set of four quantum numbers $[12,13]$ : the main quantum number $n$, the orbital quantum number $l$, the magnetic quantum 
number $m_{l}$ and the spin quantum number $m_{s}$. Therefore, bound electrons even in the same atom of matter differ from each other in energy, the shape of the electron orbital, the position of the electron orbital in atomic space, and the direction of its rotation around its own axis $[12,13]$. Having left its atom due to its ionization processes, these bound electrons of various properties become free, forming in the interatomic space an «electron cloud» with an averaged volumetric density (concentration) $n_{e m}$, numerically equal for the main conductive materials (copper, aluminum, etc.) to a value of about $10^{29} \mathrm{~m}^{-3}$ [12].

At present, in experimental physics, a number of experimentally discovered new electrophysical effects (for example, the presence of longitudinal and radial microstrata in a «metal plasma» during the electric explosion of thin metal wires in a gas medium and vacuum by pulsed current of high density $[16,17]$, the presence on the axis a high-current plasma channel during a high-voltage spark discharge in a gaseous medium of cylindrical zones with significantly higher volumetric density of free electrons (a thousand or more times) compared with its peripheral zones [18] and others) did not find their theoretical justification based on the laws of classical physics. In this regard, further deepening on the basis of the laws of quantum physics of our ideas about the nature of the longitudinal-radial flow of wave processes in metal conductors of a cylindrical configuration with electric conduction current of various types (DC, AC and pulsed) and amplitude-temporal parameters (ATPs) used in modern electrical engineering, electric power industry and high pulsed current technology, is an urgent scientific and technical task. One of the steps in solving this problem is to find the number of quantized de Broglie electron half waves of average length $\lambda_{\text {ezm }} / 2$ located along the indicated conductors with pulsed current and determining in them the corresponding average number of zones of width $\Delta z$ that differ in their increased volumetric density according to the laws of quantum physics of free electrons and correspondingly elevated temperature.

The goal of the paper is quantitative determination by calculation and experimentally of the average number $n_{0 m}$ of quantized longitudinal de Broglie electron half waves of length $\lambda_{e z m} / 2$ in a metal conductor of a cylindrical shape with pulsed axial current of high density.

1. Problem definition. Let us consider the case when axial pulsed current $i_{0}(t)$ of arbitrary ATPs with a large density $\delta_{0}(t)=i_{0}(t) / S_{0}$ averaged over its cross section $S_{0}$ flows through a thin rectilinear round continuous cylindrical conductor of radius $r_{0}$ and length $l_{0}>>r_{0}$. We use the Hartree-Fock single electron approximation $[12,13]$, which does not take into account electron-ion interactions in the internal crystalline structure of the conductor. We assume that the spatio-temporal distributions along the longitudinal coordinate $z$ and in time $t$ of drifting free electrons in the material of the investigated conductor with pulsed current $i_{0}(t)$ will approximately obey the corresponding one-dimensional Schrödinger wave equation $[12,13]$. On the basis of the quantum-mechanical approach, it is required to carry out an approximate calculation of the averaged number $n_{0 m}$ of quantized longitudinal de Broglie electron half waves of length $\lambda_{e z m} / 2$ in the considered metal conductor of a cylindrical shape with pulsed axial current $i_{0}(t)$, and also to perform using a high-power high-voltage generator of aperiodic current pulses experimental verification of the results of calculating the number $n_{0 m}$ of quantized longitudinal electron de Broglie half waves of length $\lambda_{e z m} / 2$ in this conductor.

\section{Calculation estimation of the average number} of quantized longitudinal de Broglie electron half waves in a metal conductor. To begin with, it was shown in [1, 4, 6-9] for the first time in the field of theoretical electrophysics that on the length $l_{0}$ of a metal conductor with conductivity current $i_{0}(t)$ of any kind (DC, $\mathrm{AC}$, or pulsed) an integer quantum number $n_{0}$ of longitudinal de Broglie electron half waves, satisfying the following relation always fits:

$$
n_{0}=2 l_{0} / \lambda_{e z} \text {. }
$$

Then from (4) for the desired value of the averaged number $n_{0 m}$ of quantized longitudinal electron de Broglie half waves in the metal of the conductor it follows:

$$
n_{0 m}=2 l_{0} / \lambda_{\text {ezm }}
$$

where $\lambda_{\text {ezm }}$ is the average length of the quantized longitudinal de Broglie electron wave in the metal structure of a conductor with conduction current.

From (1) we find that for the quantity $\lambda_{e z m}$ in a first approximation, an expression of the form is valid:

$$
\lambda_{\text {ezm }}=h /\left(m_{e} v_{e m}\right)
$$

where $v_{e m}$ is the average drift velocity of free electrons in a homogeneous conductor material.

It is known from atomic physics that, in the general case, $v_{e m}$ can be determined by the formula [12]:

$$
v_{e m}=\delta_{0 m} /\left(\sqrt{2} e_{0} n_{e m}\right),
$$

where $\delta_{0 m} /(2)^{1 / 2}$ is the root mean square value of the current pulse density $i_{0}(t)$ in the conductor with its amplitude $\delta 0 \mathrm{~m} ; \delta_{0 m} ; e_{0}=1.602 \cdot 10^{-19} \mathrm{C}$ is the modulus of the electric charge of an electron; $n_{e m}$ is the averaged volumetric density of drifting free electrons in a conductor.

As a result, from (5)-(7) for the average number $n_{0 m}$ of quantized longitudinal electron de Broglie half waves in a metal conductor with pulsed axial current $i_{0}(t)$ of various ATPs, we have:

$$
n_{0 m}=\sqrt{2} m_{e} \delta_{0 m} l_{0} /\left(e_{0} n_{e m} h\right) .
$$

We point out that the value of the averaged volumetric density $n_{e m}$ of drifting free electrons in the conductor metal, included in (8), is equal to the concentration $N_{0}$ of metal atoms multiplied by its valency, determined by the number of unpaired electrons on the valence electron subshells of the conductor metal atoms (for example, for copper, zinc and iron valency is equal to two $[12,19])$. The concentration $N_{0}\left(\mathrm{~m}^{-3}\right)$ of atoms in the metal of the conductor with its mass density $d_{0}\left(\mathrm{~kg} / \mathrm{m}^{3}\right)$ 
before the pulsed current $i_{0}(t)$ flows through it is determined by the formula [12]:

$$
N_{0}=d_{0}\left(M_{a} \cdot 1,6606 \cdot 10^{-27}\right)^{-1},
$$

where $M_{a}$ is the atomic mass of the conductor material included in the D.I. Mendeleev periodic system of chemical elements and almost equal to the mass number of the nucleus of the atom of the metal of the conductor, calculated in atomic units of mass (in this case, one atomic unit of mass is numerically equal to $\left.1.6606 \cdot 10^{-27} \mathrm{~kg}[13]\right)$.

In formula (8), the quantities $m_{e}, e_{0}$ and $h$ are world constants $[12,13]$, while the values $l_{0}$ and $\delta_{0 m}$ characteristic of a particular conductor can be numerically specified or determined experimentally.

It should be noted that the computational relation (8), which is simple in form of writing, was obtained in a rather rigorous way based on the known quantummechanical laws characteristic of the wave distribution of drifting free electrons in the metal of a conductor with current $i_{0}(t)[10]$.

The calculation estimation by (8) of the average number $n_{0 m}$ of quantized longitudinal de Broglie electron half waves in a steel wire $\left(r_{0}=0.8 \mathrm{~mm} ; l_{0}=320 \mathrm{~mm}\right.$; $N_{0}=8.43 \cdot 10^{28} \mathrm{~m}^{-3} ; n_{e m}=16.86 \cdot 10^{28} \mathrm{~m}^{-3}$ [10]), which is directly affected by axial aperiodic current pulse of a temporary shape $9 \mathrm{~ms} / 160 \mathrm{~ms}\left(\delta_{0 m}=0.37 \mathrm{kA} / \mathrm{mm}^{2}\right)$, shows that in this case the value of $n_{0 m}$ turns out to be numerically equal to about 9 .

It is important to note that a similar quantitative result for the value of the quantum number $n_{0 m}$ in a steel wire $(n=4)$ with current $i_{0}(t)$ was previously obtained on the basis of a calculated relation of the form [10]:

$$
n_{0 m}=n_{m} / \ln n_{m}
$$

where $n_{m}=2 n^{2}$ is the maximum value of the quantum number $n_{0}$ for Schrödinger wave $\psi$-functions describing the wave distributions of drifting free electrons in a metal conductor.

In obtaining analytical relation (10), it was assumed that the maximum number of varieties of free electrons (in their orbital $l$, magnetic $m_{l}$, and spin $m_{s}$ quantum numbers) in a conductor metal is equal to the maximum number $2 n^{2}$ of bound electrons in its atoms with the same principal quantum number $n$.

3. Experimental estimation of the average number of quantized longitudinal de Broglie electronic half waves in a metal conductor. For experimental verification of the obtained data on the choice of the averaged number $n_{0 m}$ of quantized longitudinal de Broglie electronic half waves in the conductor metal with pulsed axial current $i_{0}(t)$, we used a high-power PCG-C high-voltage generator that generates on the $R L$-load an aperiodic current pulse with amplitude of $I_{0 m}$ up to $1 \mathrm{kA}$ of temporal shape $t_{m} / \tau_{p}=9 \mathrm{~ms} / 160 \mathrm{~ms}$ ( $t_{m}$ is the time corresponding to the current amplitude $I_{0 m}$; $\tau_{p}$ is the pulse duration at the level of $0.5 I_{0 m}$ ) and the total duration $t_{0}$ of the flow through the load (conductor) is up to $1000 \mathrm{~ms}$ (Fig. 1) [20] ].

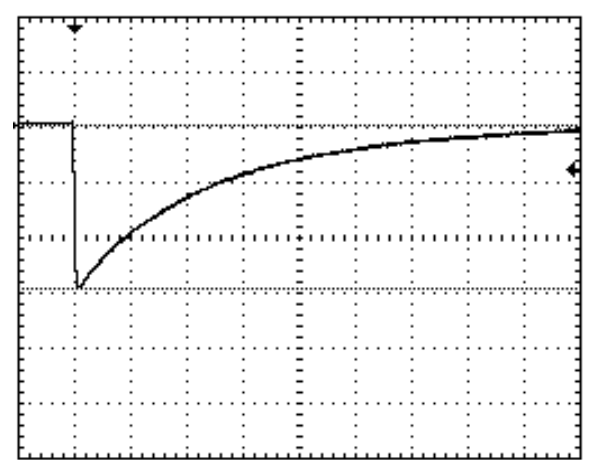

Fig. 1. Oscillogram of an aperiodic current pulse $i_{0}(t)$ of negative polarity of the temporal shape ${ }_{m} / \tau_{p}=9 \mathrm{~ms} / 160 \mathrm{~ms}$ flowing in the PCG-C discharge circuit with the equivalent of the electric load in the form of a square $2 \mathrm{~mm}$ thick aluminum sheet and plan size $500 \mathrm{~mm} \times 500 \mathrm{~mm}\left(W_{C} \approx 400 \mathrm{~kJ} ; U_{C} \approx-4.2 \mathrm{kV}\right.$; $I_{0 m} \approx-835 \mathrm{~A} ; t_{m} \approx 9 \mathrm{~ms} ; \tau_{p} \approx 160 \mathrm{~ms} ; t_{0} \approx 1000 \mathrm{~ms} ;$ vertical scale $-282 \mathrm{~A} /$ cell; horizontal scale $-100 \mathrm{~ms} / \mathrm{cell}$ ) [22]

A straight round solid steel wire $\left(r_{0}=0.8 \mathrm{~mm} ; l_{0}=\right.$ $320 \mathrm{~mm}$ ) with a thin zinc coating $\Delta_{0}=5 \mu \mathrm{m}$ thick outside was chosen as a prototype of a metal conductor (Fig. 2). The presence of a zinc coating on the indicated wire was due to the authors' assumption related to visualization of the features of the process of intense Joule heating of the wire in quantized sections of width $\Delta z$ having a refractory steel base (with a melting point of up to $1536{ }^{\circ} \mathrm{C}$ [21]) and a relatively low-melting zinc coating (with its melting point up to $419^{\circ} \mathrm{C}$ and boiling point up to $907^{\circ} \mathrm{C}$ [21]).

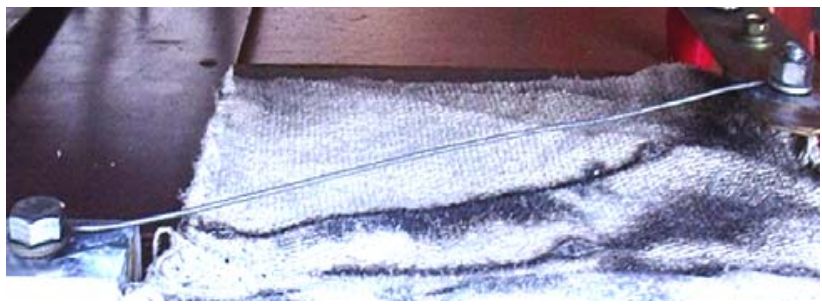

Fig. 2. General view of a round galvanized steel wire $\left(r_{0}=0.8 \mathrm{~mm} ; l_{0}=320 \mathrm{~mm} ; \Delta_{0}=5 \mu \mathrm{m} ; S_{0}=2.01 \mathrm{~mm}^{2}\right)$ placed in air above a heat-shielding asbestos cloth and rigidly fixed in the

discharge circuit of the PCG-C generator $\left(W_{C} \approx 310 \mathrm{~kJ}\right.$; $U_{C} \approx-3.7 \mathrm{kV}$ before an aperiodic current pulse of high density flows through it [9]

In the case of Joule heating with the indicated current pulse in the discharge circuit of the PCG-C type generator (with stored electric energy $W_{C}$ up to $570 \mathrm{~kJ}$ and charging voltage $U_{C}$ of its pulse capacitors ИМ2-5-140 up to $\pm 5 \mathrm{kV}$ ) of the test wire up to temperature of about $1500{ }^{\circ} \mathrm{C}$ and higher along the wire in quantized sections of width $\Delta z$, it is possible to boil the zinc coating and melt the steel base of the indicated wire. In this case, visualization of periodic formation along the wire in areas of width $\Delta z$ of expanded spheres consisting of products of boiling of a zinc coating and melting of the steel base of the wire becomes real. Running a little ahead, it can be noted that it was precisely this electrophysical phenomenon that was observed by electrophysicists on the desktop of the PCG-C type generator with a selected thin galvanized steel wire (Fig. 3). 


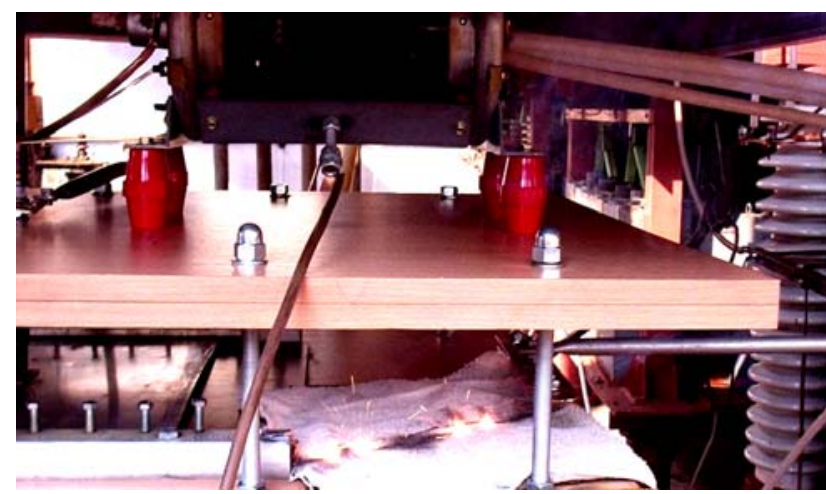

Fig. 3. External view of the desktop of a powerful high-voltage generator PCG-C and the thermal state of a galvanized steel wire $\left(r_{0}=0.8 \mathrm{~mm} ; l_{0}=320 \mathrm{~mm} ; \Delta_{0}=5 \mu \mathrm{m} ; S_{0}=2.01 \mathrm{~mm}^{2}\right)$ with four «hot» quantized zones with a width $\Delta z=7 \mathrm{~mm}$ and two «cold» longitudinal sections (isthmuses) about $27 \mathrm{~mm}$ wide after exposure to the aperiodic wire under study of the current pulse $i_{0}(t)$ of the temporary shape $t_{m} / \tau_{p}=9 \mathrm{~ms} / 160 \mathrm{~ms}$ of high density $\left(I_{0 m}=-745 \mathrm{~A} ;\left|\delta_{0 m}\right|=0.37 \mathrm{kA} / \mathrm{mm}^{2} ; n_{0 m}=9\right)$ [9]

Figure 4 shows the oscillogram of the current pulse $t_{m} / \tau_{p}=9 \mathrm{~ms} / 160 \mathrm{~ms}$, used in the study of the quantum-wave nature of the current $i_{0}(t)$ in the wire.

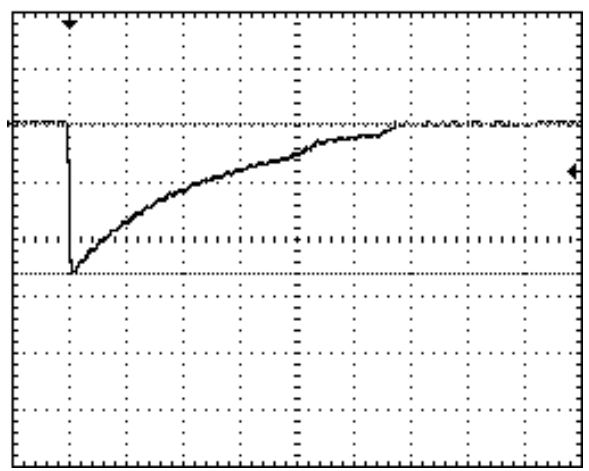

Fig. 4. Oscillogram of an aperiodic current pulse $i_{0}(t)$ of negative polarity of the temporal shape $t_{m} / \tau_{p}=9 \mathrm{~ms} / 160 \mathrm{~ms}$ of high density $\left(I_{0 m}=-745 \mathrm{~A} ;\left|\delta_{0 m}\right|=0.37 \mathrm{kA} / \mathrm{mm}^{2}\right)$ which destroys the galvanized steel wire $\left(r_{0}=0.8 \mathrm{~mm} ; l_{0}=320 \mathrm{~mm} ; \Delta_{0}=5 \mu \mathrm{m}\right.$; $S_{0}=2.01 \mathrm{~mm}^{2}$; vertical scale $-282 \mathrm{~A} /$ cell; horizontal scale $-100 \mathrm{~ms} /$ cell) [22]

According to [1-11], the longitudinal sections with a width $\Delta z$ of the wire under consideration are called relatively «hot», and the longitudinal sections (isthmuses) periodically located between its zones of width $\Delta z$ are called «cold». We point out that in $[7,9]$ it was shown that the Joule heating temperatures of these longitudinal sections of a round metal wire with the conductivity current $\mathrm{i} i_{0}(t)$ can differ up to 3.5 times. This is precisely the main danger of the thermal effect of large emergency SC currents on cable-conductor products (CCP) of electric power facilities, industrial and residential premises. Due to the localization of drifting free electrons in the current-carrying parts of the CCP in their narrow longitudinal sections of width $\Delta z$, which is not more than (3-10) $\mathrm{mm}$ in SC [10], they can quickly be intensively heated by emergency current to the ignition temperature of the CCP insulation (up to $450{ }^{\circ} \mathrm{C}$ and higher) [23]. In our opinion, this circumstance may be the main cause of many fires due to the onset of fire during sudden SCs of a power CCP not only at electric power facilities, but also in the everyday life of citizens using AC (DC) electric networks. In this regard, not only purely scientific, but also applied interests can motivate electrophysicists in solving the quantum-mechanical problem formulated above and, accordingly, achieving the previously set goals.

The main construction schemes, technical characteristics and principles of operation of a highvoltage generator of the PCG-C type were described in $[20,24-26]$. The means of high-current measuring equipment (shunts, oscilloscopes, etc.) regularly verified in the State Metrological Service that are used as part of the PCG-C generator for the experimental determination of the ATPs of the current pulse $i_{0}(t)$ flowing through the tested wire were also described there. From the experimental results obtained using the indicated PCG-C generator and from data of Fig. 3 it follows that when flowing along a bimetallic wire $\left(r_{0}=0.8 \mathrm{~mm} ; l_{0}=320 \mathrm{~mm}\right)$ with a thin external zinc coating $\left(\Delta_{0}=5 \mu \mathrm{m}\right)$ and the steel base of a powerful aperiodic current pulse of negative polarity $\left(\left|\delta_{0 m}\right| \approx\left|I_{0 m}\right| / S_{0} \approx 0.37 \mathrm{kA} / \mathrm{mm}^{2}\right)$, such a wave longitudinal distribution of drifting free electrons in the wire metal is observed, which potentially leads to the periodic appearance of nine brightly glowing «hot» longitudinal zones along the wire with a width of approximately $\Delta z=7 \mathrm{~mm}$, which take a spherical shape. Since the midpoints of each of these «hot» longitudinal zones of the wire correspond to the amplitudes of the quantized Schrödinger wave $\psi$-function $\left(n_{0}=9\right)$ [8], their own quantized de Broglie electron half waves, characterized by quantum number $n_{0 m}=9$ will correspond to them (to the middle of zones of width $\Delta z$ ).

It should be noted that due to different conditions of longitudinal heat removal from periodically arising along the studied thin cylindrical steel wire of relatively «hot» and «cold» longitudinal sections with a geometric step approximately equal to $\lambda_{e z m} / 2 \approx 34 \mathrm{~mm}$ without taking into account the two extreme «cold» and directly adjacent to the bolted joints of the sections (see Fig. 3), in the experiment performed five «hot» and eight «cold» longitudinal sections of galvanized steel wire were completely sublimated [21]. Violation of the metallic conductivity of the tested wire, caused by intense Joule heating of its current-carrying part, begins at a point in time corresponding to approximately $380 \mathrm{~ms}$ (see Fig. 4). Data in Fig. 4 shows that at a time from the beginning of the flow through the wire of the considered pulsed current $i_{0}(t)$ of about $570 \mathrm{~ms}$, the metal structure of the wire is completely destroyed and the conduction current stops flowing through the wire.

The results obtained during a high-current and hightemperature experiment using a high-power PCG-C highvoltage generator and the indicated galvanized steel wire unambiguously indicate the operability of the recommended quantum-mechanical relation (8) with an approximate choice of the average number $n_{0 m}$ of quantized longitudinal de Broglie electron half waves in a 
cylindrical conductor with pulsed axial current $i_{0}(t)$ of various ATPs.

\section{Conclusions.}

1. For the estimated forecasting of possible places of the onset of longitudinal localization of drifting free electrons in narrow sections of width $\Delta z$ of currentcarrying parts of power wires and cables of electric power facilities, industrial and residential premises, which is manifested most strongly in emergency operation of CCP with SC currents and high current densities, a new quantum-mechanical calculation relation (8) is proposed.

2. Experimental verification using powerful highcurrent high-voltage equipment and a prototype of bare galvanized steel wire with diameter of $1.6 \mathrm{~mm}$ and length of $320 \mathrm{~mm}$ (with density amplitude module of flowing for up to $570 \mathrm{~ms}$ through the wire an aperiodic current pulse of about $\delta_{0 m}=0.37 \mathrm{kA} / \mathrm{mm}^{2}$ and widths $\Delta z$ of each of the longitudinal localization regions of drifting free electrons in it up to $7 \mathrm{~mm}$ ) of the proposed relation (8), which determines, for the indicated numerical value $\delta_{0 m}$, the average number $n_{0 m}=9$ of quantized longitudinal electron de Broglie half wave length $\lambda_{\text {ezm }} / 2 \approx 34 \mathrm{~mm}$ in the metal wire, has confirmed its operability.

3. To ensure the fire safety of the power CCP in emergency operation modes, accompanied by the flow in current-carrying parts of wires and cables of alternating currents of SC with their high densities $\left(200 \mathrm{~A} / \mathrm{mm}^{2}\right.$ or more), it is necessary in the relevant regulatory documents that determine the conditions for reliable operation of the CCP in industrial and home conditions, to take into account the peculiarities of the influence of the wave nature of the distribution along the metal cores (shells) of the CCP of free electrons drifting in them on the possibility of occurrence in current-carrying parts of the CCP of short longitudinal zones of width $\Delta z$ with abnormally increased concentration of such electrons and accordingly the temperature of indicated $\mathrm{CCP}$ operation modes.

\section{REFERENCES}

1. Baranov M.I. Wave distribution of free electrons in conductor with electric current of the conductivities. Russian Electrical engineering, 2005, no.7, pp. 25-33. (Rus).

2. Baranov M.I. Energy and frequency specters of the free electrons conductor with electric current conduction. Russian Electrical engineering, 2006, no.7, pp. 29-34. (Rus).

3. Baranov M.I. Wave electronic package of a conductor with electric conduction current. Electrical engineering \& electromechanics, 2006, no.3, pp. 49-53. (Rus).

4. Baranov M.I. New physical mechanisms and approaches in the study of the formation and distribution of the electric conduction current in the conductor. Technical Electrodynamics, 2007, no.1, pp.13-19. (Rus).

5. Baranov M.I. Characteristic radial distribution of free electrons in a cylindrical conductor with varying electric current. Technical Electrodynamics, 2009, no.1, pp. 6-11. (Rus).

6. Baranov M.I. Theoretical and experimental results of research into explanation of de Broglie half-wave existence in the microstructure of an active metallic conductor. Electrical engineering \& electromechanics, 2014, no.3, pp. 45-49. (Rus). doi: 10.20998/2074-272X.2014.3.09.

7. Baranov M.I. Features heating thin bimetallic conductor large pulse current. Elektrichestvo, 2014, no.4, pp. 34-42. (Rus).

8. Baranov M.I. Quantum-wave nature of electric current in a metallic conductor and some of its electrophysical macrophenomena. Electrical engineering \& electromechanics, 2014, no.4, pp. 25-33. doi: 10.20998/2074-272X.2014.4.05.

9. Baranov M.I. The main characteristics of the wave distribution of free electrons in a thin metallic conductor with a pulse current of high density. Elektrichestvo, 2015, no.10, pp. 20-32. (Rus).

10. Baranov M.I. Izbrannye voprosy elektrofiziki: Monografija $v$ 2-h tomah. Tom 2, Kn. 1: Teorija elektrofizicheskih effektov $i$ zadach [Selected topics of Electrophysics: Monograph in 2 vols. Vol. 2, book. 1: Theory of electrophysics effects and tasks]. Kharkov, NTU «KhPI» Publ., 2009. 384 p. (Rus).

11. Baranov M.I. Izbrannye voprosy elektrofiziki. Monografiya $v 3 k h$ tomakh. Tom 2, Kn. 2: Teoriia elektrofizicheskikh effektov $i$ zadach [Selected topics of Electrophysics. Monograph in 3 Vols. Vol.2, Book 2. A theory of electrophysical effects and tasks]. Kharkiv, Tochka Publ., 2010. 407 p. (Rus).

12. Kuz'michev V.E. Zakony i formuly fiziki [Laws and formulas of physics]. Kiev, Naukova Dumka Publ., 1989. 864 p. (Rus).

13. Javorskij B.M., Detlaf A.A. Spravochnik po fizike [Handbook of physics]. Moscow, Nauka Publ., 1990. 624 p. (Rus).

14. Baranov M.I. Antologija vydajushhihsja dostizhenij v nauke i tehnike: Monografija v 3-h tomah. Tom 3 [An anthology of the distinguished achievements in science and technique: Monograph in 3 volumes. Volume 3]. Kharkiv, PhPB Panov A.N. Publ., 2016. 415 p. (Rus).

15. Baranov M.I. Refined selection of allowable cross-sections of electrical conductors and cables in the power circuits of industrial electrical equipment taking into account emergency operating modes. Electrical engineering \& electromechanics, 2019, no.3, pp. 37-43. doi: 10.20998/2074-272X.2019.3.06.

16. Stolovich N.N. Elektrovzryvnye preobrazovateli energii [Electroexplosion energy converters]. Minsk, Nauka \& Tehnika Publ., 1983. 151 p. (Rus).

17. Sobolev N.N. The study of electrical explosion of thin wires. Journal of experimental and theoretical physics, 1947, Vol.17, no.11, pp. 986-997. (Rus).

18. Ivanovskii A.V., Spirov G.M., Dudai P.V., Volkov A.A., Luk'yanov N.B., Solov'ev A.A., Volkova T.I., Lysenko V.P.. A test bench for studying the mechanisms of breakdowns of insulating gaps by short voltage pulses. Instruments and Experimental Techniques, 2003, vol. 46, no. 4, pp. 494-501. doi: 10.1023/A:1025182031922.

19. Solymar L., Walsh D. Lekcii po elektricheskim svojstvam materialov [Lectures on the electrical properties of materials]. Moscow, Mir Publ., 1991. 504 p. (Rus).

20. Baranov M.I., Koliushko G.M., Kravchenko V.I., Nedzel'skii O.S., Dnyshchenko V.N. A current generator of the artificial lightning for full-scale tests of engineering objects. Instruments and Experimental Technique, 2008, no.3, pp. 401405. doi: 10.1134/s0020441208030123.

21. Kuhling H. Spravochnik po fizike. Per. s nem. [Dictonary on Physics. Translated from German]. Moscow, Mir Publ., 1982. 520 p. (Rus).

22. Baranov M.I., Rudakov S.V. Calculation-experimental method of research in a metallic conductor with the pulse current of electronic wavepackages and de Broglie electronic half-waves. Electrical engineering \& electromechanics, 2016, no.6, pp. 45-53. doi: 10.20998/2074-272X.2016.6.08. 
23. Belorussov N.I., Saakjan A.E., Jakovleva A.I. Elektricheskie kabeli, provoda i shnury. Spravochnik [Electrical cables, wires and cords. Directory]. Moscow, Energoatomizdat Publ., 1988 536 p. (Rus).

24. Baranov M.I., Buriakovskyi S.G., Rudakov S.V. The tooling in Ukraine of model tests of objects of energy, aviation and space-rocket engineering on resistibility to action of pulsed current of artificial lightning. Electrical engineering \& electromechanics, 2018, no.4, pp. 45-53. doi: 10.20998/2074272X.2018.4.08.

25. Baranov M.I., Kniaziev V.V., Rudakov S.V. The coaxial shunt for measurement of current pulses of artificial lightning with the amplitude up to $\pm 220 \mathrm{kA}$. Instruments and Experimental Technique, 2018, vol.61, no.4, pp. 501-505. doi: 10.1134/S0020441218030156.

26. Baranov M.I., Buriakovskyi S.G., Rudakov S.V. The metrology support in Ukraine of tests of objects of energy, aviation and space-rocket engineering on resistibility to action of pulses of current (voltage) of artificial lightning and commutation pulses of voltage. Electrical engineering \& electromechanics, 2018, no.5, pp. 44-53. doi: 10.20998/2074272X.2018.5.08.

Received 19.11.2019

M.I. Baranov ${ }^{1}$, Doctor of Technical Science, Professor,

S.V. Rudakov ${ }^{2}$, Candidate of Technical Science, Associate Professor,

${ }^{1}$ Scientific-\&-Research Planning-\&-Design Institute «Molniya», National Technical University «Kharkiv Polytechnic Institute», 47, Shevchenko Str., Kharkiv, 61013, Ukraine, phone +380 577076841 ,

e-mail: baranovmi@kpi.kharkov.ua

${ }^{2}$ National University of Civil Protection of Ukraine,

94, Chernyshevska Str., Kharkiv, 61023, Ukraine, phone +380 577073438 ,

e-mail: serg_73@i.ua

How to cite this article:

Baranov M.I., Rudakov S.V. Calculation-experimental determination of the average number of quantized longitudinal electron de Broglie half waves in a cylindrical conductor with pulsed axial current. Electrical engineering \& electromechanics, 2020, no.2, pp. 33-39. doi: 10.20998/2074-272X.2020.2.05. 